\title{
The Effects of Focused And Unfocused Written Corrective Feedback on The Grammatical Accuracy of Beginner EFL Learners
}

\author{
Fateme Saeb \\ English Department, Faculty of Humanities, Shahid Rajaee University, Tehran, Iran \\ E-mail address: f.saeb1384@gmail.com
}

Received: 12-10-2013

doi:10.7575/aiac.ijalel.v.3n.2p.22
Accepted: 28-11-2013

Published: 01-03-2014

URL: http://dx.doi.org/10.7575/aiac.ijalel.v.3n.2p.22

\begin{abstract}
The study reported in this paper aimed at investigating the efficacy of written corrective feedback (CF) in improving beginner EFL learners' grammatical accuracy. It also compared the effects of focused and unfocused written CF on the learners' grammatical accuracy. Seventy-nine beginner EFL students formed a control group $(n=29)$ and two experimental groups (focused $=25$, unfocused $=25$ ). The use of the third person singular ' $\mathrm{s}$ ' morpheme for verbs was selected as the target structure to be treated through the provision of the written CF. The focused group received corrections concerning the use of the ' $\mathrm{s}$ ' morpheme while the unfocused group received corrections for their all types of errors. The results indicated a significant improvement in accuracy for the two experimental groups from pretest to posttest. Also, the difference between the focused and unfocused groups in the posttest was not significant. These results suggested that providing written CF was effective for improving learners' grammatical accuracy and that focused and unfocused written CF were not of differential effect in this regard.
\end{abstract}

Keywords: Grammatical accuracy, Written corrective feedback, Focused and unfocused feedback

\section{Introduction}

Since 1996 when Truscott published his article "The case against grammar correction in L2 writing classes", researchers have investigated and discussed the effectiveness of written corrective feedback for developing learners' linguistic accuracy. Truscott (1996) strongly claimed that grammar correction is not useful in writing classes and should be discarded since it is clearly ineffectual and even harmful. Ferris (1999; cited in Bitchener et al., 2005) disagreed with Truscott's position claiming that with regard to the growing research results indicating ways in which effective error correction can help learners, correction could not be abandoned. Chandler (2003) also came up with the argument that the studies cited by Truscott should be examined strictly and that the reported results can be construed diversely.

When he did a meta-analysis of corrective feedback (CF) research, Truscott (2007) dismissed the efficacy of written corrective feedback once more and concluded that correction might only have an unsubstantial harmful effect on the learners' accuracy. He proposed that the use of error correction is a misstep and that the question "how effective is correction?" should be replaced by "how harmful is correction?"(p.271).

A number of studies have investigated the efficacy of written corrective feedback (Ashwell, 2000; Fathman and Walley, 1990; Ferris and Roberts, 2001; Kepner, 1991; Polio et al., 1998, cited in Sheen et al., 2009). But many of them show some sort of methodological deficiencies, like the lack of a control group or a pretest. A usually stated criticism against some of these studies is that they measured students' improvement in revision of previous texts rather than new pieces of writing, which is, according to Truscott (2007), a poor criterion of progress.

A few recent studies, however, have tried to amend this problem through measuring students' linguistic accuracy in new pieces of writing and have provided evidence for the efficacy of CF in improving grammatical accuracy (Bitchener et al., 2005; Bitchener, 2008; Bitchener and Knock, 2009, 2010; Ellis et al., 2008; Evans et al., 2011; Sheen, 2007). These studies have studied not only the efficacy of CF per se, but also the efficacy of its different types. Two types of CF which has been studied frequently in recent years are "direct" and "indirect" CF. Direct corrective feedback can be defined as the provision of the correct linguistic form to the student above his or her error. Indirect corrective feedback, on the other hand, can refer to any process through which the teacher specifies that in some way an error has been made without explicit attention drawn to it (Bitchener and Knock, 2009).

Bitchener et al. (2005) compared the effects of different types of CF (direct CF with and without oral conferencing) on linguistic accuracy. They restricted providing written CF to three types of errors (prepositions, simple past and definite article) and found that both types of direct CF influenced the accuracy significantly but that this result was only obtained with the definite article and the past tense. Chandler (2003) also explored the difference between direct and indirect CF. She asked her participants to write autobiographical texts over a period of time. The effect of written CF 
was assessed both on new and revised texts and it was found that direct written CF led to a significant progress in students' accuracy.

Another feature which has drawn less attention and is investigated less is that of "focused" and "unfocused" CF. In focused $\mathrm{CF}$, the provision of corrective feedback is limited to a specific error type and other errors are overlooked. In unfocused $\mathrm{CF}$, all error types are corrected. There are some theoretical ground for predicting focused CF to be more effective than unfocused CF. "If attention and understanding are important for acquisition, as cognitive theories of L2 acquisition have claimed, then focused CF is clearly better equipped to produce positive results"( Ellis et al., 2008, p.356).

Few studies, to date, have investigated the effect of focused and unfocused CF on linguistic accuracy. In one of such studies, Sheen (2007) examined the effect of focused CF on the improvement of 91 adult ESL learners' accuracy in using definite and indefinite articles. Three groups took part in the study: a direct-only correction group, a direct metalinguistic correction group, and a control group. Sheen found that both treatment groups did much better than the control group on the immediate posttests, but the direct metalinguistic group performed better than the direct-only correction group in the delayed posttests. The results showed that written CF focusing a single linguistic item improved learners' accuracy, especially when metalinguistic feedback was provided.

In another study, Ellis et al. (2008) compared the effects of focused and unfocused written CF on the accuracy of Japanese university students in using the indefinite and definite articles in written narratives. The focused group received correction of just article errors in three pieces of narratives while the unfocused group received correction of article errors as well as other errors. Both groups gained from pre-test to post-tests on both an error correction test and on a test involving a new piece of narrative writing and also outperformed a control group, which received no correction, on the second posttest. The CF was equally effectual for the focused and unfocused groups.

In a more recent study, Sheen et al. (2009) investigated the effects of direct focused CF, direct unfocused CF and writing practice alone on the accurate use of grammatical forms among adult ESL learners. Four groups were formed: focused written CF group, unfocused written CF group, writing practice group and a control group. The results showed that all three experimental groups gained in grammatical accuracy over time in all the posttests. The focused group achieved the highest accuracy gain scores followed by, in order, the written practice group, and the unfocused group. The results indicated that unfocused $\mathrm{CF}$ is of limited pedagogical benefit whereas focused $\mathrm{CF}$ can be helpful to grammatical accuracy in L2 writing.

Clearly, there is an inconsistency between the results of these studies, since Ellis et al. (2008) found that focused and unfocused groups benefited equally from CF and Sheen et al. (2009) found the reverse. This inconsistency indicates an obvious need for further research investigating the efficacy of focused as opposed to unfocused CF. Such was the motivation for the study reported in this paper. Other incentives for this study which are also its distinguishing features are as follows: First, since the majority of studies concerning written CF have been done within ESL contexts, there's a need to do such research studies in EFL contexts as well. Otherwise, we will have no evidence of gaining analogous results in the two contexts. Second, as the research in this field has, so far, been limited to measuring the effectiveness of CF for certain linguistic error domains and categories (definite and indefinite articles, past tense and prepositions), there remains a need for investigating the efficacy of CF on different domains of linguistic accuracy. Thus, a different error category (the use of third person singular 's' for verbs) was chosen as the target structure. Finally, since much of the available research has been conducted with intermediate and advanced level students, we do not know the extent to which CF can be helpful for students with a lower level of proficiency. So this study was conducted with a group of beginner students. Based on the aforementioned points, the study reported below aimed to answer these research questions: a) Does written CF help beginner EFL students to become more accurate in the use of third person singular 's' for verbs ? b) Is there a significant difference in the effect of unfocused and focused CF directed at using third person singular 's' for verbs?

\section{The target structure}

Though it may seems a straightforward, simple rule to be learnt, the experience of many teachers shows that the use of third person singular ' $s$ ' for verbs is a quite difficult grammatical feature to be mastered by students. A series of research by Pienemann and Johnston (1987) has led them to conclude that the acquisition of grammatical structures is determined by how difficult they are to process psycholinguistically, rather than how simple or complex they are grammatically. They illustrate this with the third person's' morpheme. Grammatically, this is a fairly simple item, but it is notoriously difficult for learners to learn. Pienemann and Johnston suggest that the difficulty originates from the fact that the form of the verb is ruled by the person and number of the subject noun and does not stand by itself (Nunan, 1994). Given the difficulty associated with acquiring third person's' morpheme, and its repeated and obligatory use in different sentences, it provides us a suitable choice to investigate the effectiveness of written corrective feedback.

\section{Method}

\subsection{Participants}

The participants in this study were three intact classes of 79 female EFL students at the first grade of high school. Their age ranged between 14 and 15 years. They had studied English as a school subject for three years at junior high school and were attending English classes three hours a week in high school. Their proficiency in English was at the beginning level. Five students were attending extra classes for their English outside the school, however, since they had started them recently, they were still at the beginning level. The focus of the textbook covered in the course was on vocabulary 
and grammar. Two of the classes were randomly assigned to the two experimental groups: focused $(\mathrm{n}=25)$ and unfocused $(\mathrm{n}=25)$. The third class was assigned to a control group $(\mathrm{n}=29)$.

\subsection{Design}

The study employed a quasi-experimental design with a pretest- treatment- posttest design using intact classes as described in the previous section. There were two experimental and one control group. The treatment involved the provision of two different types of written corrective feedback, i.e., the focused and unfocused corrections during two tasks. The focused group received corrections exclusively for their errors concerning the use of the third-person singular 's' morpheme whereas the unfocused group received corrections for their all types of errors. All three groups took an error correction test as the pretest and posttest.

\subsection{Tasks and the error correction test}

Two tasks were given to the students during two sessions as the treatment. In each session, the students were asked to watch an animation film in English and write a summary describing what the main character of the film did. These summary writings were taken as the tasks in this study. The students had to write their summaries in simple present tense. Writing the summary included using verbs in which the use of 's' was required as well as the verbs that did not need it. The two films which were shown during two sessions were The Gruffalo (2010) and Bambi II (2006).

The test used as the pre and posttest was a teacher-made error correction test. It consisted of 14 items. Each item consisted of two sentences, one of which contained a grammatical error. The students were asked to identify the incorrect sentence and write it correctly. Ten out of 14 items involved sentences with errors concerning the third person 's'. Four items served as distracters, containing errors of other types. The reliability of the error correction test was tested in a pilot study yielding the Cronbach alfa of .81 .

\subsection{Procedure}

On day one, the pretest was administered. In the next session, which was a week later, the treatment was provided, i.e., the first film was shown in the classroom followed by a brief discussion about what happened in the film. The purpose of the discussion was to make sure that all of the students have understood what the main character had done. The teacher provided them with the new vocabulary necessary for describing what happened in the film and wrote them on the board. Then the students were asked to write their summaries. There was no time limit and the students were allowed to consult their textbook or a dictionary. On the third session, again a week later, the tasks were returned to the students. The focused group received corrections only for verbs that needed the 's' and other errors were ignored. The unfocused group received corrections for all kinds of errors. The difference between the corrections that the two groups received is illustrated in the following example:

\section{Example}

A student in the focused group wrote a sentence as follows:

The mouse brown want to run away from the Gruffalo but he can't.

The correction was provided only for the incorrect use of the verb "want" and the incorrect use of the adjective "brown" was not corrected. But such a sentence in the unfocused group received correction for both errors.

The corrections were written above the errors with a red pen. The students were asked to look at their errors carefully for about 5 minutes but no more explanation or instruction was provided. Then the second film was shown and the second task was done by the students in the same way as the previous one. On the fourth session, the students received corrections for the second task and after that the posttest was administered. The procedure for the control group was the same except that they did not receive any correction for their errors. They were only provided with general comments in the form of letters A, B, C or D, which meant "excellent", "good", "acceptable" and "weak" respectively, a system which is usually used for evaluating their homework and the students were acquainted with. During the whole period of the study, the students in the three groups were provided with no explicit instruction on the use of the targeted structure.

\subsection{Analysis}

The error correction test was scored on a discrete item basis. One point was given for each correct detection of errors. The distractors were excluded. Thus the perfect score for the test was 10 points. All scores were put into SPSS (2010) and the following descriptive and inferential statistics were computed to answer the two research questions: first, descriptive statistics for the two administrations of the error correction test were computed. Then the scores for the two administrations of the error correction test were analyzed using a mixed between-within subjects analysis of variance (SPANOVA) and t-tests.

\section{Results}

Table 1 presents the means and standard deviations for the error correction pretest and posttest for the three groups. The experimental groups and the control group improved their scores from the pretest to posttest. This improvement is shown in Fig.1. SPANOVA results revealed that there were significant time differences, $F(1,76)=74.19, p<.0005$, partial eta squared $=.49$ which can be considered a large effect size according to standards set by Cohen (1988). There were significant group differences, $F(2,76)=34.28, p<.0005$, partial eta squared $=.47$. Also, the scores of both focused group ( $\mathrm{t}(24)=-5.53, p<.0005)$ and the unfocused group $(\mathrm{t}(24)=-6.19, p<.0005)$ improved significantly from pretest to posttest, while no significant difference was found between the control group's scores in the pretest and 
the posttest $(\mathrm{t}(28)=-1.49, p=.14)$. A comparison of the two experimental groups' scores on posttest showed no significant differences between them $(\mathrm{t}(48)=.450, p=.65)$.

Table 1. Descriptive statistics for the error correction test

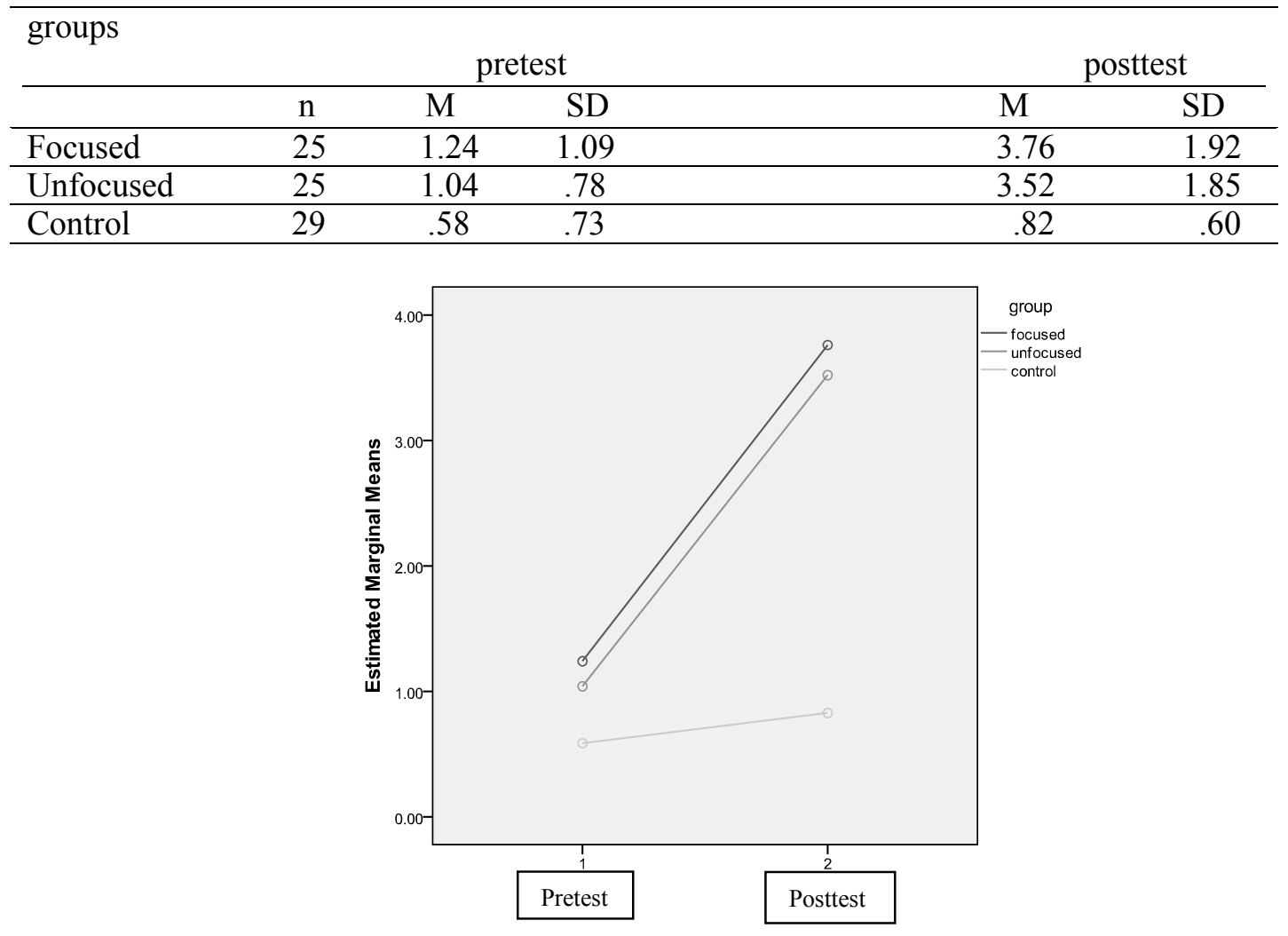

Fig. 1. Three groups' means on the pretest and the posttest

\section{Discussion}

Research question 1 investigated whether written CF helped beginner EFL students to become more accurate in the use of third person singular 's' for verbs. Examining the results for the error correction pretest and posttest can answer this research question. The students' ability to monitor errors using their metalinguistic knowledge is considered here as a measure of their grammatical accuracy. It was found that both experimental groups outperformed the control group significantly in the posttest.

This result reveals that receiving written corrective feedback helped learners to improve their grammatical accuracy concerning the use of third person singular 's' morpheme for verbs (the large effect size for time differences should also be kept in mind in this regard). Two facts regarding the students' improvement support such a conclusion: first, the students in none of the three groups were given explicit instruction or explanation on the use of third person singular 's', and second, they were aware that their scores on the error correction tests had no influence on their course grade. This means that they had no instrumental motivation to try to improve their scores. Overall, in line with the results of some recent CF studies (Bitchener, 2008; Bitchener \& Knoch, 2008; Ellis et al., 2008; Sheen, 2007; Sheen et al., 2009), this result is contrary to Truscott's $(1996,2007)$ claim that grammar correction is ineffective and the practice for error correction is a failure.

The second research question asked whether there was a differential effect for focused and unfocused CF directed at using third person singular ' $\mathrm{s}$ ' for verbs. An examination of the two experimental groups' scores on the posttest indicated that there was not such an effect. The focused group's mean on the posttest was slightly higher than the unfocused group's mean, but the very same superiority was also present in the pretest. Thus, the difference between the focused and unfocused groups on the posttest did not reach statistical significance. This implies that both types of CF were equally effective in improving learners' grammatical accuracy. This result is in agreement with the findings of Ellis et al. (2008) who also found no significant difference between focused and unfocused CF in improving learners' accuracy in using the indefinite and definite articles. However, it is inconsistent with the results of Sheen et al. (2009) who found the focused CF most effective for improving the accurate use of grammatical forms by ESL learners. As obvious, the question of the relative effectiveness of focused and unfocused written $\mathrm{CF}$ is still far from conclusive. Further researches would be needed to settle the issue.

\section{Conclusion and Limitations}

The findings of the present study revealed that written CF can assist beginner EFL learners to improve their grammatical accuracy and that this effect does not differ according to whether the CF is provided focused or unfocused. However, there are a few limitations regarding the design and the procedure of the study which should be borne in mine 
while considering the results. First, using an error correction test as the measure of grammatical accuracy may be criticized, since the inclusion of a writing test was not feasible due to the participants' low level of proficiency. The lack of a delayed posttest is also a shortcoming of the current study. Although the results indicated that providing written $\mathrm{CF}$ improved learners' grammatical accuracy, it is unknown whether this improvement would be stable over time. Finally, only two tasks were completed by the students in the experimental groups and the treatment period was relatively short which contributes to the few number of overall corrections received by the students. This was due to limitations on the school schedule and the use of equipments. With tasks continued over a longer period of time we might come to different results, particularly regarding the relative values of focused and unfocused CF. Interestingly however, this limitation can be regarded as a strength point of this study. While one might expect that more overall corrections are needed to lead to a significant increase in accuracy, we now know that with a relatively small number of corrections, the same result would be viable. Respecting the abovementioned limitations, there remains a clear need for replication studies. In particular, it would be helpful to conduct similar studies on beginner EFL learners with posttests to test the durability of the results.

As for the contribution of this study to the existing literature on written $\mathrm{CF}$, it made at least one point clear: discrete, rule-based linguistic features like the use of third person singular ' $s$ ' morpheme can be treated successfully in beginner EFL learners through the provision of written corrective feedback. From a pedagogical point of view, with respect to the results of this study, foreign language teachers may feel confident that their beginner students would benefit from receiving written corrective feedback over a short period of time and would increase their grammatical accuracy in, at least, discrete, rule-based linguistic features. Considering the limitations, I would not wish to generalize this finding to other more complicated linguistic features before more sound research studies explore the efficacy of written CF in treating such features.

\section{References}

Bitchener, J. (2008). Evidence in support of written corrective feedback. Journal of Second Language Writing 17, $102-$ 118. http://dx.doi.org/10.1016/j.jslw.2007.11.004

Bitchener, J., Knoch, U. (2008). The value of a focused approach to written corrective feedback. ELT Journal 6, 204211.

Bitchener, J., Knoch, U. (2009). The relative effectiveness of different types of direct written corrective feedback. System, 37(2), 322-329. http://dx.doi.org/10.1016/j.system.2008.12.006

Bitchener, J., Knoch, U. (2010). The contribution of written corrective feedback to language development: A ten month investigation. Applied Linguistics 31, 193-214. http://dx.doi.org/10.1093/applin/amp016

Bitchener, J., Young, S., Cameron, D. (2005). The effect of different types of corrective feedback on ESL student writing. Journal of Second Language Writing 9, 227-258.

Chandler, J. (2003). The efficacy of various kinds of error feedback for improvement in the accuracy and fluency of L2 student writing. Journal of Second Language Writing 12, 267-296. http://dx.doi.org/10.1016/S1060-3743(03)00038-9

Cohen, J. (1988). Statistical Power Analysis for the Behavioral Sciences. second ed. Erlbaum, Mahwah, NJ.

Ellis, R., Sheen, Y., Murakami, M., Takashima, H. (2008). The effects of focused and unfocused written corrective feedback in an English as a foreign language context. System 36, 353-371. http://dx.doi.org/10.1016/j.system.2008.02.001

Evans, N. W., Hartshorn, K. J., Strong-Krause, D. (2011). The efficacy of dynamic written corrective feedback for university matriculated ESL learners. System 39, 229- 239. http://dx.doi.org/10.1016/j.system.2011.04.012

Nunan, D. (2002). Syllabus Design. Oxford University Press.

Pienemann, M., Johnston, M. (1987). Factors influencing the development of language proficiency. In D. Nunan (Ed.), Applying second language acquisition research (pp. 45-141). Adelaide: National Curriculum Research Centre, Adult Migrant English Program.

Sheen, Y. (2007). The effect of focused written corrective feedback and language aptitude on ESL learners' acquisition of articles. TESOL Quarterly 41, 255-283.

Sheen, Y., Wright, D., Moldawa, A. (2009). Differential effects of focused and unfocused written correction on the accurate use of grammatical forms by adult ESL learners. System 37, 556-569.

http://dx.doi.org/10.1016/j.system.2009.09.002

Truscott, J. (1996). The case against grammar correction in L2 writing classes. Language Learning 46, $327-369$.

http://dx.doi.org/10.1111/j.1467-1770.1996.tb01238.x

Truscott, J. (2007). The effect of error correction on learners' ability to write accurately. Journal of Second Language Writing 16, 255-272. http://dx.doi.org/10.1016/j.jslw.2007.06.003 